\title{
The effects of Solidago canadensis water extracts on maize seedling growth in association with the biomass allocation pattern
}

\author{
Xiao qi Ye ${ }^{1}$, Jin liu Meng ${ }^{1}$, Ming Wu ${ }^{\text {Corresp. } 1}$ \\ 1 Research Station of Hangzhou Bay Wetland Ecosystems, National Forestry Bureau / Institute of Subtropical Forestry, Chinese Academy of Forestry, \\ Hangzhou, P.R.China \\ Corresponding Author: Ming Wu \\ Email address: hangzhoubay@126.com
}

Background. Solidago canadensis L. is an aggressive exotic plant species in China that has potential allelopathic effects on competing plant species. Hormetic effects are frequently observed in studies of allelopathy; however, the mechanisms of such effects need to be elucidated. Allelopathic compounds may affect the growth of recipient plants via alteration of biomass allocation patterns or photosynthetic capacity. The aim of this study was to determine how water extracts from $S$. canadensis affected the shoot and root growth of recipient plants and whether the underlying mechanism was related to the biomass allocation pattern or photosynthetic gas exchange capacity. Methods. The water extracts from $S$. canadensis shoots at twelve different concentrations in the range of 0 $0.25 \mathrm{~g} / \mathrm{ml}$ were applied thrice in 9 days to maize seedlings cultivated in silica sand. The growth (shoot height, leaf length and area and root length) and biomass accumulation and allocation (specific leaf area (SLA), leaf area ratio (LAR) and leaf mass ratio (LMR)) were compared among maize seedlings exposed to different treatment concentrations. Gas exchange (photosynthetic light response curve) was measured and compared among maize seedlings exposed to three concentrations of water extract $(0,0.0125$ and $0.2 \mathrm{~g} / \mathrm{ml})$ before and after the first application, and seedling growth was measured after the third and final application. Results. The growth of seedlings (shoot height, leaf length and area and root length) was promoted at concentrations below $0.125 \mathrm{~g} / \mathrm{ml}$ and inhibited at concentrations above this level $(P<0.05)$. The pattern of change in biomass accumulation and allocation was similar to that of shoot growth, but biomass accumulation and allocation was not significantly affected by the water extract treatments $(P>0.05)$. The water extract treatments did not significantly affect the photosynthetic capacity $(P>$ 0.05), but the dark respiration rate was higher in the low-dose treatment than that in the high-dose treatment. Shoot height was positively correlated with the biomass allocation indicators SLA and LAR $(P<0.05)$ but not with LMR $(P>0.05)$. Conclusions. The results 
suggested that the effects of the water extracts from S. canadensis were highly dependent on the concentration, with the growth of maize seedlings promoted at low concentrations of water extracts. The effects of the water extracts on the growth of maize seedlings were mainly due to the effects on the LAR, the allocation to leaf area growth, whereas the effects of the water extracts on leaf gas exchange capacity can not explain variation of seedling growth. Thus, the stimulation of plant growth was very likely due to increased biomass allocation towards the shoot. 
1 The effects of Solidago canadensis water extracts on maize

2 seedling growth in association with the biomass allocation

3 pattern

4 Xiao qi Ye, Jin liu Meng, Ming $\mathrm{Wu}^{*}$

5 Research Station of Hangzhou Bay Wetland Ecosystems, National Forestry Bureau/Institute of Subtropical Forestry, Chinese Academy of Forestry, Hangzhou,

6 Zhejiang, P.R. China

8 Corresponding author:

9 Ming $\mathrm{Wu}$

10 Daqiao Road 73, Hangzhou, Zhejiang Province, 311400, P.R. China

11 E-mail address: hangzhoubay@126.com 
27 Abstract

Background. Solidago canadensis L. is an aggressive exotic plant species in China that has potential allelopathic effects on competing plant species. Hormetic effects are frequently observed in studies of allelopathy; however, the mechanisms of such effects need to be elucidated. Allelopathic compounds may affect the growth of recipient plants via alteration of biomass allocation patterns or photosynthetic capacity. The aim of this study was to determine how water extracts from $S$. canadensis affected the shoot and root growth of recipient plants and whether the underlying mechanism was related to the biomass allocation pattern or photosynthetic gas exchange capacity.

Methods. The water extracts from S. canadensis shoots at twelve different concentrations in the range of $0-0.25 \mathrm{~g} / \mathrm{ml}$ were applied thrice in 9 days to maize seedlings cultivated in silica sand. The growth (shoot height, leaf length and area and root length) and biomass accumulation and allocation (specific leaf area (SLA), leaf area ratio (LAR) and leaf mass ratio (LMR)) were compared among maize seedlings exposed to different treatment concentrations. Gas exchange

41 (photosynthetic light response curve) was measured and compared among maize seedlings exposed to three concentrations of water extract $(0,0.0125$ and $0.2 \mathrm{~g} / \mathrm{ml})$ before and after the first application, and seedling growth was measured after the third and final application.

Results. The growth of seedlings (shoot height, leaf length and area and root length) was

45 promoted at concentrations below $0.125 \mathrm{~g} / \mathrm{ml}$ and inhibited at concentrations above this level $(P$ $46<0.05)$. The pattern of change in biomass accumulation and allocation was similar to that of 
47 shoot growth, but biomass accumulation and allocation was not significantly affected by the

48 water extract treatments $(P>0.05)$. The water extract treatments did not significantly affect the

49 photosynthetic capacity $(P>0.05)$, but the dark respiration rate was higher in the low-dose

50 treatment than that in the high-dose treatment. Shoot height was positively correlated with the

51 biomass allocation indicators SLA and LAR $(P<0.05)$ but not with $\operatorname{LMR}(P>0.05)$.

52 Conclusions. The results suggested that the effects of the water extracts from $S$. canadensis were

53 highly dependent on the concentration, with the growth of maize seedlings promoted at low

54 concentrations of water extracts. The effects of the water extracts on the growth of maize

55 seedlings were mainly due to the effects on the LAR, the allocation to leaf area growth, whereas

56 the effects of the water extracts on leaf gas exchange capacity can not explain variation of

57 seedling growth. Thus, the stimulation of plant growth was very likely due to increased biomass

58 allocation towards the shoot.

60 Solidago canadensis L. (Asteraceae), which originates from North America, has successfully

61 invaded southeastern China. This species usually forms large monocultures and causes

62 substantial yield loss of crop plants (Liu et al., 2010). Although how the invasiveness of this

63 species develops is unknown, the hypothesis that allelopathy may contribute to the success of the

64 species is supported by some existing evidence (Abhilasha et al., 2008; Yuan et al., 2012). The

65 rhizome extract of $S$. canadensis imposed hormetic effects on both the growth and physiological

66 activity of lettuce seedlings in a laboratory experiment (Zhang et al., 2012). Therefore, whether

67 the allelochemicals of $S$. canadensis increase or decrease crop yields may depend on their 
concentration in soils, which should be considered when explaining the interaction of $S$. canadensis with native species or crop plants.

Hormesis refers to the stimulation of organism performance that occurs at low levels of exposure to agents that are harmful or toxic at high levels of exposure (Forbes, 2000; Calabrese and Baldwin, 2001). The hormetic effects of herbicides on plant growth have been observed many times (Cedergreen, 2008a), while more recently, the hormetic effects of phytotoxins have received attention due to their close association with exotic plant invasion (Prithiviraj et al., 2007; Zhang et al., 2012).

Many mechanisms to explain hormetic effects have been proposed (Prithiviraj et al., 2007; Duke et al., 2006). The induction of defense mechanisms induced by free radicals of oxygen can lead to increased growth at low doses of phytotoxic chemicals (Kovalchuk et al., 2003). For example, a low dose of $( \pm)$-catechin, which is produced by the invasive weed Centaurea maculosa, induced moderate increases in reactive oxygen species in meristems and much greater biomass accumulation (Prithiviraj et al., 2006). Moreover, reactive oxygen species have proven to be essential for cell elongation in plants (Rodríguez et al., 2002). Some chemicals that can affect plant secondary metabolism are associated with the synthesis of cell wall fibers at low doses (Duke et al., 2006). For example, glyphosate inhibits the shikimate pathway, the source of lignin precursors, and might preferentially inhibit lignin synthesis at low, nonherbicidal doses, making cell walls more elastic for longer periods during development (Duke et al., 2006). The roles of photosynthetic capacity in explaining growth promotion effects by low-dose chemicals have also been carefully examined. Compared with untreated barley plants (Cedergreen, 2008b), 
89 when sprayed with low doses of glyphosate, barley plants had a higher relative growth rate (RGR)

90 that was partly attributed to the increased photosynthesis rate (Cedergreen and Olesen, 2010).

91 Increaded photosynthesis rate was also found in the promotion effects of cadmium, a heavy

92 metal, on the growth of several plant species (Jia et al., 2015; Pereira et al., 2016). Nevertheless,

93 enhanced photosynthesis was not observed when growth was stimulated in cucumber plants

94 treated with several herbicides (Wiedman and Appleby, 1972) or in rice plants treated with

95 microcystins (Liang and Wang, 2015). These inconsistent results suggest that other critical

96 responses explain the dose effects on plant growth, such as biomass allocation patterns.

97 Considering that the plant RGR consists of a morphological component, the leaf area ratio

98 (LAR), and a physiological component, the net assimilation rate (NAR) (Poorter, 1990), an

99 increase in the RGR under a low dose of a hormetic substance is not necessarily caused by an

100 increase in the photosynthesis rate but can also be due to an increase in the allocation to leaf area.

101 Indeed, some hypotheses state that the stimulatory growth at low concentrations is due to altered

102 resource allocation between shoots and roots (Duke et al., 2006). Therefore, to best explain the

103 hormetic effect of growth stimulation, the physiological factor (assimilation capacity) and the

104 biomass allocation factor are both important to consider.

105 The objective of this study was to first test the effects of the shoot extract of S. canadensis

106 on the growth and biomass accumulation of maize seedlings and, second, to elucidate the

107 possible mechanisms underlying the promotion or inhibitory effects. Specifically, we

108 investigated how the extracts of $S$. canadensis affected the growth and biomass accumulation and

109 allocation patterns of treated maize seedlings. We correlated the maize seedling shoot height to 
110 biomass allocation patterns (LAR, specific leaf area (SLA) and leaf mass ratio (LMR)) to

111 determine whether the biomass allocation pattern could explain the promotion or

112 inhibition observed. We also compared the photosynthetic capacity under the concentrations that

113 either promoted or inhibited growth to determine whether the variation in photosynthetic

114 capacity could explain the hormetic effects.

Materials and methods

117

118

119

120

121

122

123

124

125

126

127

128

129

130

\section{Water extract preparation}

In September 2017, when S. canadensis plants started to flower, the shoots of $S$. canadensis plants were collected from fields and immediately transported to the laboratory, where the inflorescence was removed. The shoots were collected during this period because in this stage, $S$. canadensis reportedly accumulates the highest content of phenolics, which are assumed to be the major allelopathic substances in this species (BaležEntienè, 2015). As shoots are proven to be most allelopathic part of S. canadensis (BaležEntienè, 2015), only the allelopathic effects of shoots were investigated in this study. The procedure for the water extraction of shoots followed the modified methods from Meiners (2014). The shoots were cleaned with tap water and dried at room temperature. Afterwards, the shoots were cut into $8 \mathrm{~mm}$ pieces. The water extracts were made with a ratio of $1 \mathrm{~g}$ of shoot pieces: $4 \mathrm{ml}$ of distilled water in beakers. The extraction was performed an incubation chamber at $30-31^{\circ} \mathrm{C}$ for $24 \mathrm{hr}$. Subsequently, the extraction solution was filtered through 2 layers of cotton and stored in a refrigerator at $4^{\circ} \mathrm{C}$ until ready for use.

\section{Maize seedling culture}


131 We used maize plants as the target species, due to the frequent interaction of this crop with

132 S. canadensis and the large yield losses associated with S. canadensis invasion (Liu et al., 2010).

133 Commercially sold maize (Zea mays L.) seeds (var. Meiyu 8, Hainan Lvchuan Seeds Co., Ltd.,

134 China) were germinated in $9 \mathrm{~mm}$ Petri dishes, with thirty seeds placed in each dish. After

135 germination for 6 days, and when the first leaf was fully open, 72 seedlings with similar size

136 (plant height and leaf number) were transplanted into $180 \mathrm{ml}$ pots containing $120 \mathrm{~g}$ of silica sand,

137 with one plant in each pot. For each treatment concentration, 6 replicate plants were used. The

138 maize seedlings were grown for another 4 days, and then, the first of the water extract

139 supplement treatments was applied. The seeds were germinated and the seedlings cultured in a

140 plant growth chamber, with a constant irradiance of $250 \mu \mathrm{mol} \cdot \mathrm{m}^{2} \cdot \mathrm{s}^{-1}$ (photosynthetically active

141 radiation, PAR) above the shoots and an air temperature of $24^{\circ} \mathrm{C}$ for $12 \mathrm{hr}$ during the day and $14218^{\circ} \mathrm{C}$ for $12 \mathrm{hr}$ at night.

143

144

145

146

147

148

149

150

151

\section{Experimental design and water extract supplement treatments}

To prepare the water extract concentration gradient, the original shoot water extract was diluted with distilled water. The final concentrations were as follow: $0,0.0125,0.025,0.05$, $0.075,0.1,0.125,0.15,0.175,0.2,0.225$ and $0.25 \mathrm{~g}$ shoot equivalent $/ \mathrm{ml}$ (hereafter referred to as $\mathrm{g} / \mathrm{ml})$. The seedlings were supplemented with the water extract from the top of the pots. Every 3 days for 9 days, each pot was treated with $100 \mathrm{ml}$ of nutrient solution (1/4-strength Hoagland's solution) and $4 \mathrm{ml}$ of extract solution. For a total of 9 days, the water extract treatments continued. The treatments were applied under the same growth chamber conditions as described above. 
152

\section{Gas exchange measurement}

The gas exchange measurements were performed on maize seedlings treated with three concentrations of water extract: 0 (CK, control), $0.0125 \mathrm{~g} / \mathrm{ml}$ (Low concentration) and $0.2 \mathrm{~g} / \mathrm{ml}$ (High concentration). The measurements were conducted on the day preceding the commencement of treatments (0 day) and on the following 3 days. Net photosynthetic rates (Pn) and respiration rates $(\mathrm{Rd})$ were measured on the fourth fully expanded leaf with an open-type gas exchange system (LI-6400, Li-Cor Inc., Lincoln, NE). Photosynthetic light response curves were individually analyzed for the 6 replicated seedlings. The PAR for the light response curve was as follows: $2500,2000,1500,100,500,300,100,50$ and $0 \mu \mathrm{mol} \cdot \mathrm{m}^{2} \cdot \mathrm{s}^{-1}$, and the flow rate was 0.5 $1 \cdot \mathrm{min}^{-1}$. The stability waiting time in the light response curve autoprogram was set as $60 \sim 120 \mathrm{~s}$. Before each measurement, the leaves were light activated for $20 \mathrm{~min}$ at the PAR of 2500 $\mu \mathrm{mol} \cdot \mathrm{m}^{2} \cdot \mathrm{s}^{-1}$. Light-saturated net photosynthetic rate $\left(\mathrm{P}_{\max }\right)$, apparent quantum yield (AQY) and dark respiration $\left(\mathrm{R}_{\mathrm{d}}\right)$ were determined by using the following model (Lewis, Olszyk and Tingey, 1999):

$$
\mathrm{P}=\frac{\mathrm{P}_{\max } P \text { PFD }}{\mathrm{K}+\mathrm{PPFD}}-\mathrm{R}_{\mathrm{d}}
$$

where $\mathrm{P}$ is the simulated photosynthesis rate calculated with the above model, PPFD is the photosynthetic photon flux density, and $\mathrm{K}$ is equal to the PPFD required to produce one-half of the light-saturated photosynthetic rate.

\section{Growth measurement}

When the photosynthesis measurement was finished, the maize seedlings had developed three to four true leaves. When the photosynthesis measurement was finished, the maize seedlings have developed three to four true leaves. The maize seedlings were then harvested after the third extract application. The height of each plant was measured with a ruler, while the roots were washed with distilled water to remove any silica sand. The roots and leaves were then 
176

177

178

179

180

181

182

183

184

185

186

separated from the plants and scanned with a Microteck Scanwizard 5 (Microtek International, Inc., Taiwan). Next, the total root length and the total leaf length and area were analyzed with the programs Winrhizo and Winfolia (Regent Instruments Inc., Canada), respectively. Plant materials were then oven dried at $60^{\circ} \mathrm{C}$ for $72 \mathrm{hr}$, and the mass weight of the leaf, stem and root for each seedling was measured. The SLA, LMR and LAR were calculated as follow: SLA = total leaf area/total leaf weight; LMR = total leaf weight/whole plant weight; and LAR = total leaf area/whole plant weight.

\section{Data analysis and statistics}

Compared with the controlled plants (water extract concentration $=0$ ), the change in plant height, total root length, total leaf length and area, SLA, LMR, LAR and biomass was calculated as follows: (Growth of treated plants - growth of controlled plants)/growth of controlled plants $\times 100 \%$. The effects of the water extract concentration on plant growth were analyzed with oneway ANOVA (analysis of variance). The gas exchange characteristics (light-saturated Pn, Rd and AQY) were analyzed with two-way ANOVA with water extract concentration and treatment time (days) as fixed factors. Linear regression analysis of biomass based on SLA, LMR and LAR was performed with the data pairs of the plant height value and the SLA, LMR and LAR values of each individual plant. All analyses were conducted in the SPSS 16.0 statistical software package (SPSS 16.0, SPSS Inc., Chicago, IL).

\section{Results}

The effect of $S$. canadensis water extracts on maize seedling growth and biomass 
197 accumulation followed a hormetic pattern, i.e., seedling growth and biomass accumulation 198 increased at low concentrations $(0.0125-0.125 \mathrm{~g} / \mathrm{ml})$ and decreased at high concentrations $199(0.125-0.25 \mathrm{~g} / \mathrm{ml})$ (Figs. 1 and 2), with the most remarkable stimulatory effects at $0.0125 \mathrm{~g} / \mathrm{ml}$ 200 (Figs. 1 and 2). The effects of water extracts on plant height, total leaf length, total leaf area and total root length $(P<0.05$, Table 1$)$ were significant, whereas the effects on the biomass accumulation of leaf, stem, root and whole plant and on the resource allocation indexes SLA, LMR, LAR and root/shoot ratio were not significant $(P>0.05$, Table 1$)$.

Hormetic-like effects were also observed on SLA and LAR (Fig. 3), but the effect of treatment concentration on these indexes was not significant (Table 1). The maximum photosynthesis rate and apparent quantum efficiency were not significantly different among the three different water extract treatments: CK $(0 \mathrm{~g} / \mathrm{ml})$, low concentration $(0.0125 \mathrm{~g} / \mathrm{ml})$ and high concentration $(0.2 \mathrm{~g} / \mathrm{ml})(P>0.05$, Table 2, Fig. 4). However, those plants that received the low dose of water extract had higher respiration rates than those of the two other treatments $(P<0.05$,

Fig. 4). Although SLA, LAR and LMR were not significantly affected by the water extract treatments, the pattern of change in these morphological parameters was similar to that of plant shoot height. The regression analysis indicated that plant shoot height was closely associated with SLA and LAR $(P<0.01)$ but not with LMR $(P>0.05)$ (Fig. 5).

\section{Discussion}

216 We observed that the water extracts of $S$. canadensis shoots had hormetic-like effects on the 
218 Zhang et al. (2012), suggesting that the potential allelopathic effects of the water extracts on

219 recipient plants were highly dependent on the concentration. In other studies, negative 220 allelopathic effects of S. canadensis are reported (Butcko and Jensen, 2002; Abhilasha et al., 221 2010). The variation in the effects of water extracts on recipient plant growth may be due to the tissues studied, methods used for preparation, concentration dose of water extract applied, growth conditions and species of the recipient plant. Our study showed that identifying the potential allelopathic compounds and determining their actual concentrations in the environment are critical when regarding the allelopathic effects of $S$. canadensis.

We observed hormetic-like effects of the water extracts on the growth and biomass accumulation of maize seedlings. The shoot and root growth was promoted significantly by the low-dose water extract, but maize seedling biomass accumulation was not significantly promoted. The lack of significant effects on biomass accumulation was possibly due to the relatively low light availability $\left(250 \mu \mathrm{mol} \cdot \mathrm{m}^{2} \cdot \mathrm{s}^{-1}\right)$ and low $\mathrm{CO}_{2}$ concentration (ambient $\mathrm{CO}_{2}$ concentration, approximately $380 \mathrm{ppm}$ ) applied. Cedergreen and Olesen (2010) showed that the promotion effects on barley plant growth with low-dose glyphosate application were absent or much weaker at relatively low light availability or $\mathrm{CO}_{2}$ concentrations. We expected that an increase in the photosynthesis rate would explain the enhanced growth; however, no significant effects on the photosynthetic capacity of maize seedlings were observed (Fig. 3), although the respiration rate was indeed higher for the low water extract concentration of $0.0125 \mathrm{~g} / \mathrm{ml}$ than that of the control and the $0.2 \mathrm{~g} / \mathrm{ml}$ treatment. Simijlar to our results, application of low concentration microcystins,

a group of cyanotoxins produced by cyanobacteria, also stimulated the growth (plant height and 
239 biomass accumulation) in rice seedlings, but did not stimulate photosynthesis rate of the plants

240 (Liang and Wang, 2015).

241 Two explanations are possible for the lack of significant effects on the photosynthetic

242 capacity. First, unlike glyphosate, the shoot water extract of $S$. canadensis is a mixture of diverse compounds that includes small to large molecules with differential dose-effect curves or that even cause effects in contrasting directions. Therefore, the integrated action of these compounds may lead to less pronounced effects compared with the unique effects of glyphosate (Duke et al., 2006). These compounds in $S$. canadensis have been categorized as phenolics, flavones and saponins (Yuan et al, 2013; BaležEntienè, 2015). The other explanation is that the activity of

Rubisco, RuBP regeneration or the use rate of triose phosphate was not enhanced in the maize

leaves due to the similar leaf $\mathrm{N}$ content. The leaf photosynthesis rate under ambient air conditions is most limited by Rubisco activity and leaf nitrogen content (Sinclair and Horie, 1989; Makino, 2003). Thus, the photosynthesis rate in our study was not affected because the water extract treatment may not have increased the leaf nitrogen content..

The increase in the dark respiration rate of maize seedlings at the low concentration of water extract, which is similar to that in barley plants treated with a low dose of glyphosate (Cedergreen and Olesen, 2010), may explain the increase in maize plant height, leaf area and length and root length. In hormesis, the increase in root and shoot growth is interpreted as an adaptive mechanism of escape from stressful conditions (Duke et al, 2006). The increase in respiration rate indicated increased metabolic activity in response to the toxic water extract, 259 which may enable the recipient plant to activate detoxification, inactivation or 
260

261

262

263

264

265

266

267

268

269

270

271

272

273

274

275

276

277

278

279

280

compartmentalization processes (Cedergreen and Olesen, 2010). In addition, we observed a

pattern of allocating more resources towards aboveground growth at low water extract concentrations, which could be a strategy to escape from the harmful underground conditions, even though root growth was also promoted at low water extract concentrations. Other environmental factors, such as mineral nutrient supplements, play important roles in growth stimulation by increasing the aboveground biomass allocation parameters, such as SLA and LAR (Poorter and Nagel, 2000). The increases in SLA and LAR suggested greater allocation to shoot and leaf growth, which can increase the photosynthetic area relative to other nonphotosynthetic organs. The concentration range that stimulated shoot growth overlapped with the range that stimulated SLA and LAR (Figs. 1, 2 and 3). Furthermore, the positive correlations between SLA and LAR and plant shoot height suggested that the promotion of growth with the low-dose water extract was due more to the increase in assimilation area than to the increase in assimilation capacity (per unit leaf area). The increase in SLA may be explained by either a moderate increase in reactive oxygen species (Prithiviraj et al., 2006) or an inhibition of lignin synthesis (Duke et al., 2006), which both occur at low-dose treatments. In another study on the hormeticlike effects of $S$. canadensis extracts, the ability of the recipient plant to cope with stress, as indicated by the activities of SOD (Superoxide dismutase) and other enzymes, was stimulated at low extract concentrations but was inhibited at high concentrations (Zhang et al, 2012), suggesting that the mechanisms also act at the physiological level.

Although whether a stimulatory effect occurs in fields where $S$. canadensis invades is not clear, fast growth together with high SLA and LAR could have significant ecological 
281

282

283

284

285

286

287

288

consequences for those plants that are affected by low-dose phytotoxins because these plants with relatively fast growth rates may have increased vulnerability to mechanical stress or herbivory (Belz et al., 2011). These secondary consequences should also be considered when explaining crop yield loss caused by exotic plant invasion.

In summary, the water extract of $S$. canadensis had significant effects on maize seedling growth, suggesting that the interactions of $S$. canadensis with crops or native species in fields could be affected. The effects were highly dependent on the concentration; the stimulated growth caused by the low-concentration water extract of $S$. canadensis shoots on maize seedlings growth could be explained mostly by the biomass allocation patterns (leaf SLA and LAR) but not by the gas exchange capacity. Therefore, the investigation of the concentration of allelopathic compounds of $S$. canadensis in the field is critical to the study of their possible effects on native species.

\section{References}

Abhilasha D, Quintana N, Vivanco J, Joshi J. 2008: Do allelopathic compounds in invasive Solidago canadensis s.l. restrain the native European flora? Journal of Ecology, 96:993-1001.

BalebEntienë L. Secondary metabolite accumulation and phytotoxicity of invasive species Solidago canadensis L. during the growth period. 2015. Allelopathy Journal, 35(2):217-226.

Belz RG, Cedergreen N, Duke SO. 2011. Herbicide hormesis - can it be useful in crop production? Weed Research, $51: 321-332$

Butcko VM, Jensen RJ. Evidence of tissue-specific allelopathic activity in Euthamia Graminifolia and Solidago Canadensis (Asteraceae)[J]. American Midland Naturalist, 2002, 148(2):253-262. 
302 Calabrese EJ, Baldwin LA. 2001. U-Shaped dose-responses in biology, toxicology and public health. Annual 303 Review of Public Health, 22:15-33.

304 Cedergreen N. 2008a. Herbicides can stimulate plant growth. Weed Research, 48:429-438.

305 Cedergreen N. 2008b. Is the growth stimulation by low doses of glyphosate sustained over time? Environmental 306 Pollution, 156:1099-1104.

Cedergreen N, Olesen CF. 2010. Can glyphosate stimulate photosynthesis? Pesticide Biochemistry and Physiology, $96: 140-148$.

Duke SO, Cedergreen N, Velini ED, Belz RG. 2006. Hormesis: is it an important factor in herbicide use and allelopathy? Outlooks on Pest Management, 17:29-33.

Forbes VE. Is hormesis an evolutionary expectation? 2000. Functional Ecology, 14:12-24.

Kovalchuk, I., Filkowski J, Smith K, Kovalchuk O. 2003. Reactive oxygen species stimulate homologous recombination in plants. Plant Cell and Environment, 26: 1531-1539. subjected to elevated atmospheric $\mathrm{CO}_{2}$ and temperature. Tree Physiology, 19: 243-252.

Jia L, Liu ZL, Chen W, Ye Y, Yu S, He XY. Hormesis effects induced by cadmium on growth and photosynthetic 34(1):13-21.

Liang CJ, Wang WM. Response and recovery of rice (Oryza sativa) seedlings to irrigation with microcystincontaminated water[J]. Environmental Earth Sciences, 2015, 73(8):4573-4580. canadensis and corn growth. Acta Agriculturae Shanghai, 26:80-82. 
323

324

325

326

327

328

329

330

331

332

333

334

335

336

337

Makino M. Rubisco and nitrogen relationships in rice: leaf photosynthesis and plant growth. 2003. Soil Science \& Plant Nutrition, 49(3):319-327.

Meiners SJ. Functional correlates of allelopathic potential in a successional plant community. 2014. Plant Ecology, 215:661-672.

Pereira MP, Rodrigues LCDA, Corrêa FF, Castro EMD, Ribeiro VE, Pereira FJ.Cadmium tolerance in Schinus molle trees is modulated by enhanced leaf anatomy and photosynthesis[J]. Trees, 2016, 30(3):807-814.

Prithiviraj B, Perry LG, Dayakar BV, Vivanco JM. 2007. Chemical facilitation and induced pathogen resistance mediated by a root-secreted phytotoxin. New Phytologist, 173:852-860.

Poorter H. 1990. Interspecific variation in relative growth rate: on ecological causes and physiological consequences. In: Lambers H, Cambridge ML, Konings H, Pons TL, ed. Causes and consequences of variation in growth rate and productivity of higher plants. The Hague: SPB Academic.

Poorter H, Nagel O. 2000. The role of biomass allocation in the growth response of plants to different levels of light, $\mathrm{CO}_{2}$, nutrients and water: a quantitative review. Australian Journal of Plant Physiology, 27:595-607.

Sinclair T R, Horie T. Leaf nitrogen, photosynthesis, and crop radiation use efficiency: A Review[J]. Crop Science, 1989, 29(1):90-98.

Sun BY, Tan JZ, Wan ZG, Gu FG, Zhu MD. Allelopathic effects of extracts from Solidago canadensis L. against seed germination and seedling growth of some plants[J]. Journal of Environmental Sciences, 2006, 18(02):97102.

Rodríguez AA, Grunberg KA, Taleisnik EL. 2002. Reactive oxygen species in the elongation zone of maize leaves are necessary for leaf extension. Plant Physiology, 129:1627-1632.

Yuan YG, Wang B, Zhang SS, Tang JJ, Tu C, Hu SJ, Yong JWH, Chen X. 2013. Enhanced allelopathy and 
344 competitive ability of invasive plant Solidago canadensis in its introduced range. Journal of Plant Ecology, 2013, $345 \quad 6: 231-235$.

346 Wiedman SJ, Appleby AP. 1972. Plant growth stimulation by sublethal concentrations of herbicides. Weed $347 \quad$ Research, 12:65-74.

348 Zhang SS, Wang B, Zhang L, Yu GD, Tang JJ, Chen X. 2012. Hormetic-like dose response relationships of 349 allelochemicals of invasive S. canadensis L. Allelopathy Journal, 29:151-160.

\section{Acknowledgments}

352 We thank the editors and reviewers for their constructive comments and suggestions. We thank

Prof. Xin Chen for her kind help in revision of the manuscript. 
Figure 1

Growth of the maize seedlings exposed to the different water extract concentration treatments

(A) Plant height, (B) Total leaf length, (C) Total leaf area and (D) Total root length. 0-12 on the horizontal axis corresponds to water extract concentration: $0,0.0125,0.025,0.05,0.075$, $0.1,0.125,0.15,0.175,0.2,0.225$ and $0.25 \mathrm{~g} / \mathrm{ml}$, respectively. The points in the plot refer to mean \pm standard error.
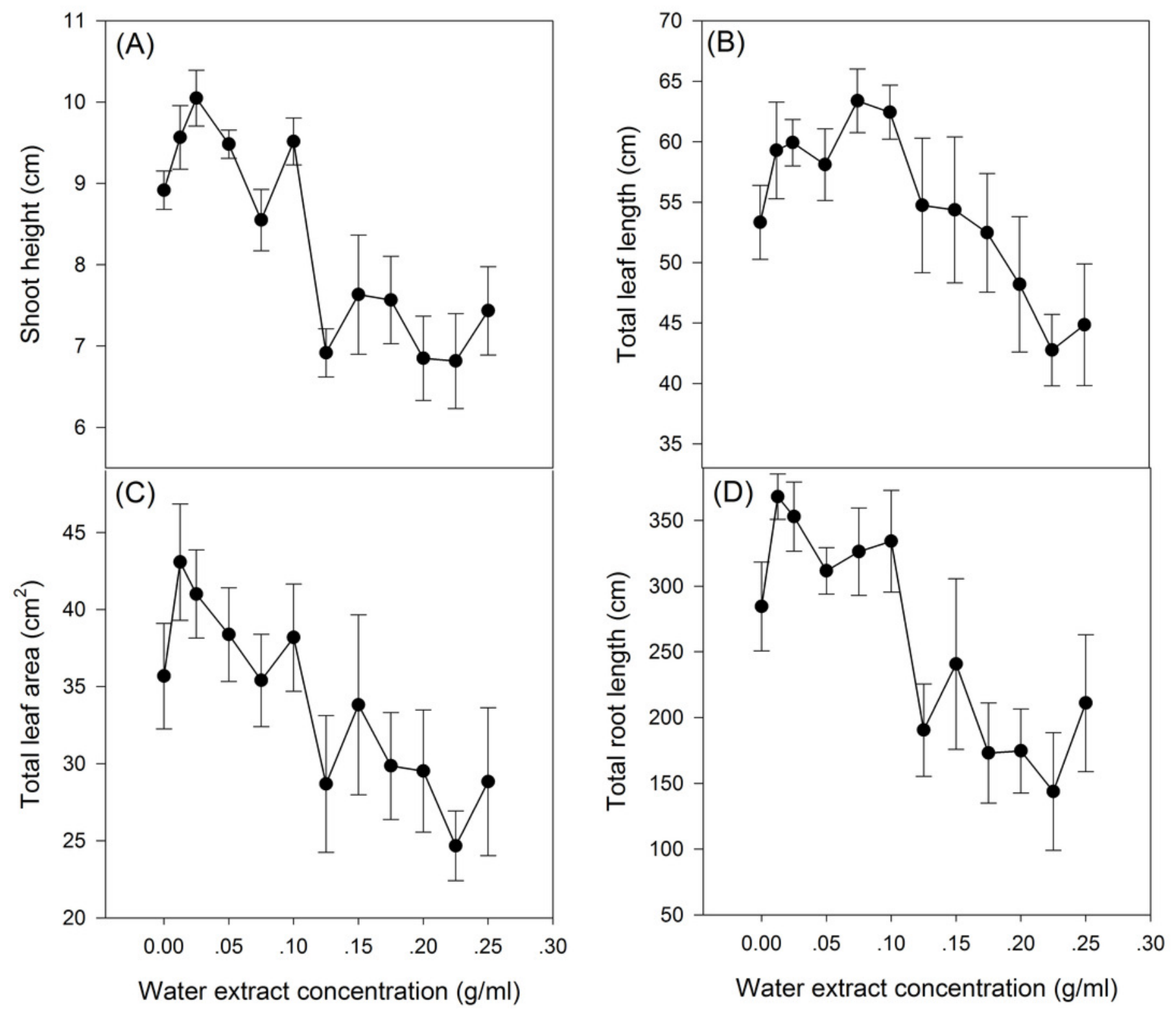
Figure 2

Biomass of the maize seedling treated with different concentrations of shoot water extract from $S$. canadensis.

Biomass of (A) Stem, (B) Leaf, (C) Root and (D) Whole plant of the maize seedlings.
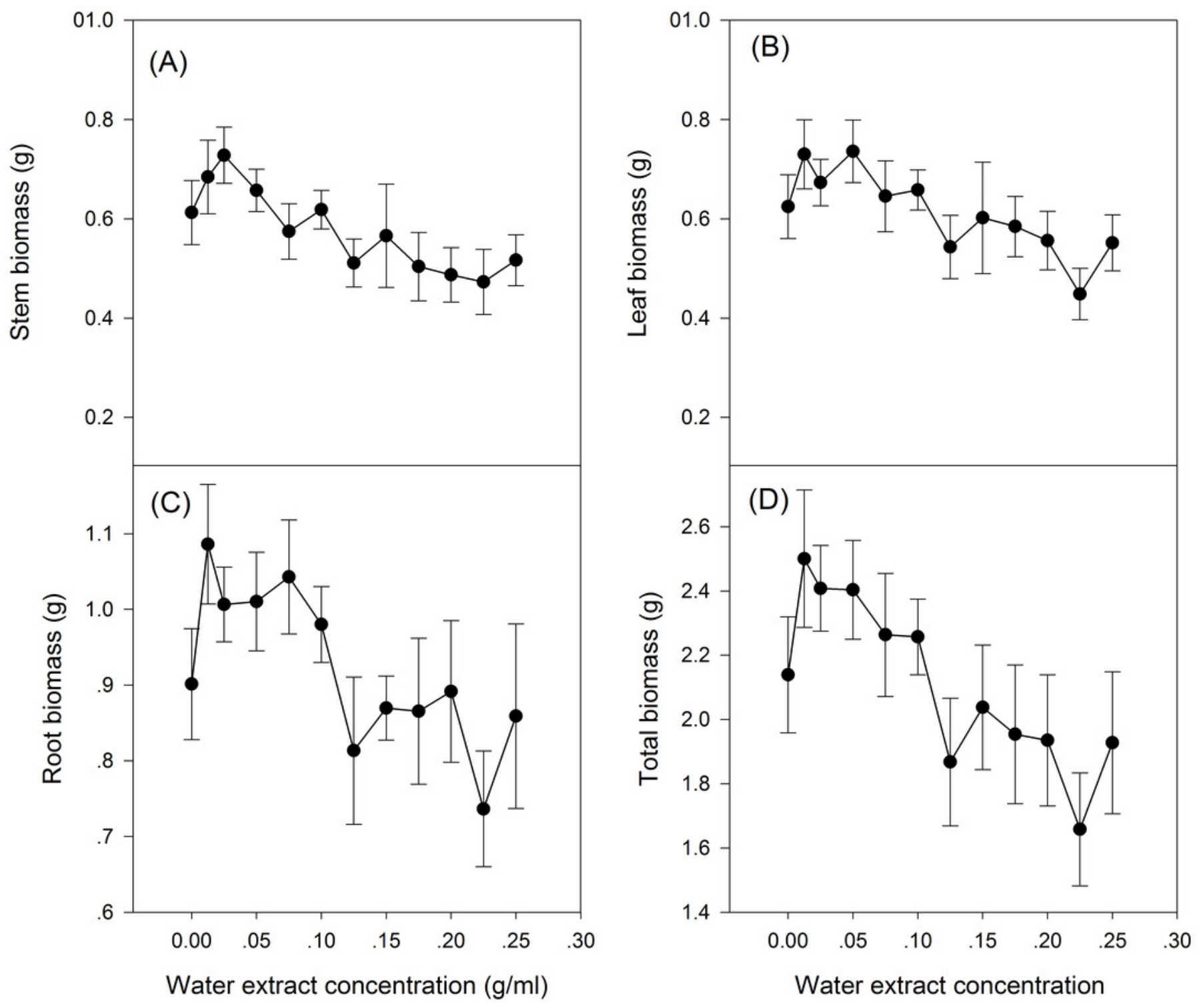
Figure 3

Biomass allocation to leaf of the maize seedlings treated with different concentrations of shoot water extract from S. canadensis.

(a) Specific leaf area (SLA), (b) Leaf mass ratio (LMR) and (c) Leaf area ratio (LAR). The points in the plot stand refer to mean \pm standard error.
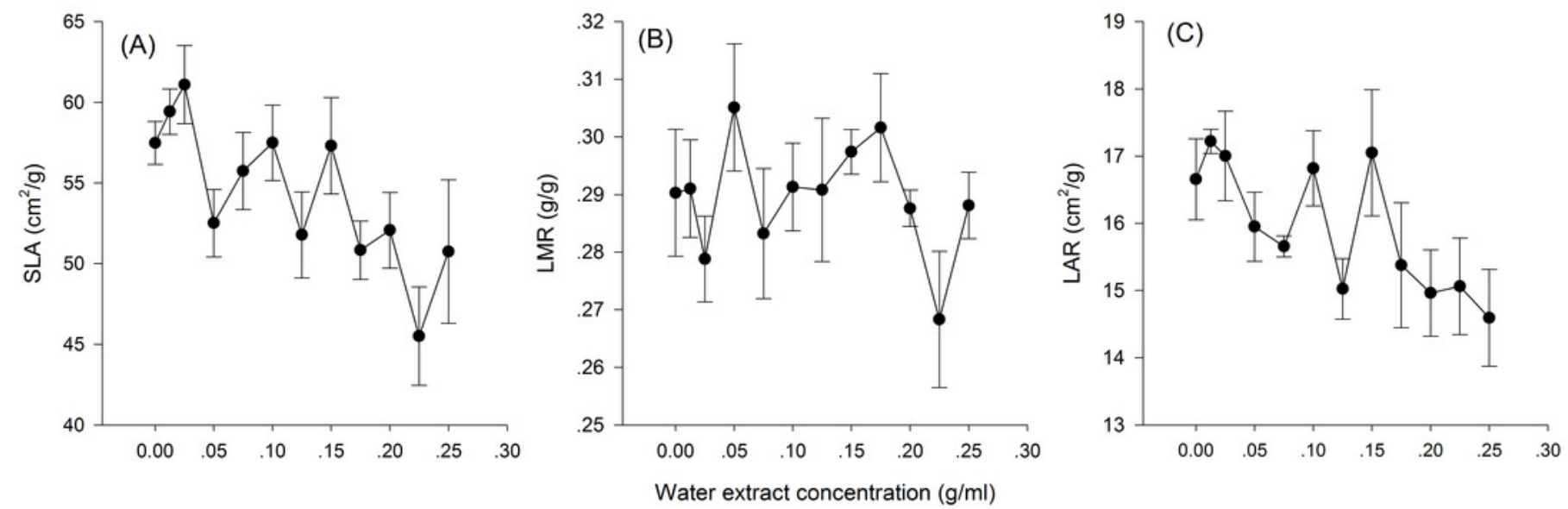
Figure 4

Gas exchange characteristics of the maize seedlings treated with the three shoot water extract concentrations from S. canadensis.

CK (control, $0.000 \mathrm{~g} / \mathrm{ml})$, Low concentration $(0.0125 \mathrm{~g} / \mathrm{ml})$ and High concentration $(0.2 \mathrm{~g} / \mathrm{ml})$.

(A) $\mathrm{P}_{\max }$, light-saturated photosynthesis rate, (B) AQY, apparent quantum efficiency and (C)

$R_{d}$, dark respiration rate. The points in the plot stand refer to mean \pm standard error.
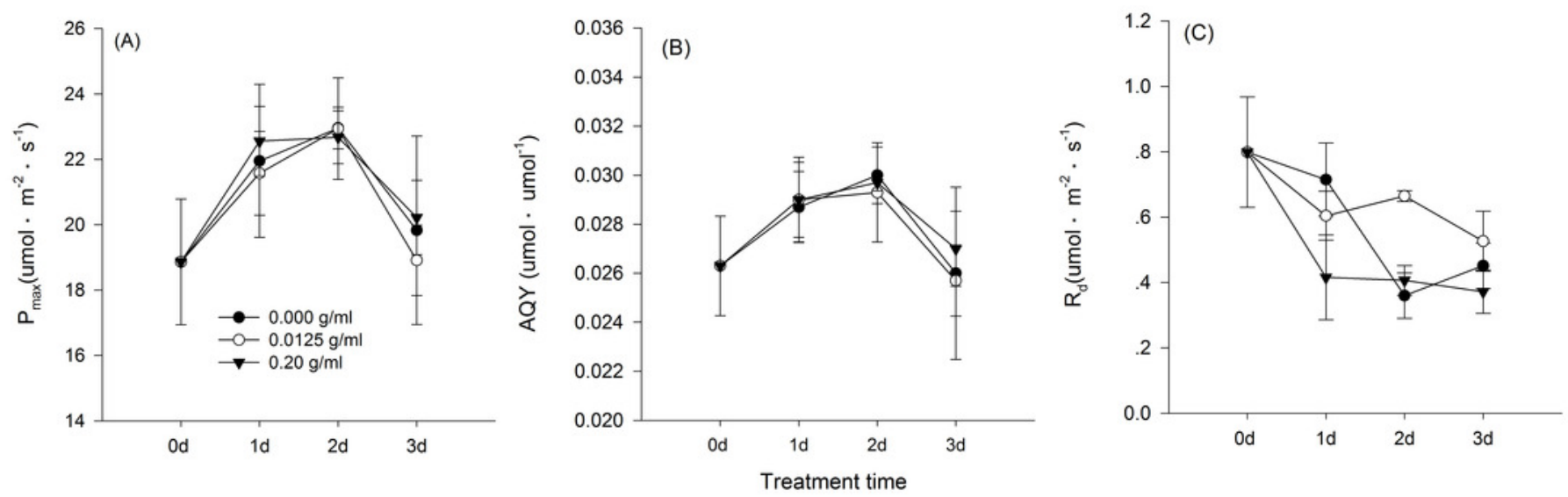
Figure 5

Regression of biomass allocation to leaf against the plant shoot of the maize seedlings treated with different concentrations of shoot water extract from S. canadensis.

(A) Specific leaf area (SLA), (B) Leaf mass ratio (LMR) and (C) Leaf area ratio (LAR) of the maize seedlings treated with different concentrations of shoot water extract from $S$. canadensis.
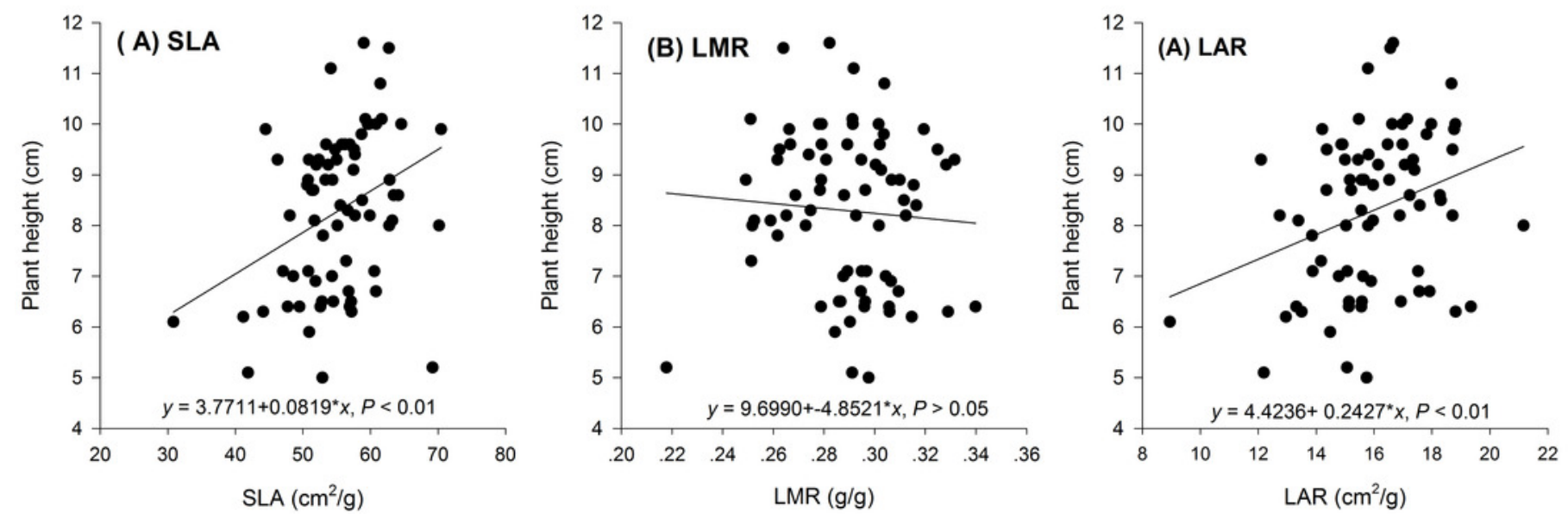


\section{Table $\mathbf{1}$ (on next page)}

One-way ANOVA analysis for growth and biomass accumulation of the maize seedlings treated with different concentrations of water extracts from shoots of the $S$. canadensis plants

${ }^{z} P$ is the siginificance of the statistics. When $P<0.05$, it is considered to be significant. ${ }^{*} P<$ $0.05,{ }^{* *}, \mathrm{P}<0.01,{ }^{* * *} \mathrm{P}<0.001$. When $\mathrm{P}>0.05$, it is considered to be not significant. ${ }^{\text {ns }}$ indicates no significance. 
3 Table 1 One-way ANOVA analysis for growth and biomass accumulation of the maize seedlings treated with

4 different concentrations of water extracts from shoots of the $S$. canadensis plants

\begin{tabular}{|c|c|c|c|c|c|c|c|}
\hline Growth & $d f$ & $F$ & $P^{Z}$ & Growth & $d f$ & $F$ & $P^{Z}$ \\
\hline Plant height & 11,59 & 7.242 & $0.000^{* * *}$ & Stem mass & 11,59 & 1.763 & $0.081^{\mathrm{ns}}$ \\
\hline Total leaf length & 11,59 & 2.551 & $0.010^{*}$ & Leaf mass & 11,59 & 1.597 & $0.123^{\mathrm{ns}}$ \\
\hline Total leaf area & 11,59 & 2.204 & $0.026^{*}$ & Root mass & 11,59 & 1.187 & $0.316^{\mathrm{ns}}$ \\
\hline Total root length & 11,59 & 4.284 & $0.000^{* * *}$ & Whole plant mass & 11,59 & 1.494 & $0.158^{\mathrm{ns}}$ \\
\hline LMR & 11,59 & 1.173 & $0.325^{\text {ns }}$ & LAR & 11,59 & 1.502 & $0.155^{\mathrm{ns}}$ \\
\hline SLA & 11,59 & 1.891 & $0.059^{\mathrm{ns}}$ & Root/shoot ratio & 11,59 & 1.017 & $0.433^{\text {ns }}$ \\
\hline
\end{tabular}




\section{Table 2 (on next page)}

Two-way ANOVA analysis for gas exchange characteristics of the maize seedlings treated with different concentrations of water extract from shoots of the $S$. canadensis plants.

CK $(0.000 \mathrm{~g} / \mathrm{ml})$, Low concentration $(0.0125 \mathrm{~g} / \mathrm{ml})$ and High concentration $(0.2 \mathrm{~g} / \mathrm{ml}) ;{ }^{z} P$ is the siginificance of the statistics. When $P<0.05$, it is considered to be significant. ${ }^{*} P<0.05,{ }^{* *}, P$ $<0.01,{ }^{* * *} P<0.001$. When $P>0.05$, it is considered to be not significant, and ${ }^{\text {ns }}$ indicates no significance. 
2 Table 2 Two-way ANOVA analysis for gas exchange characteristics of the maize seedlings treated with

3 different concentrations of water extract from shoots of the $S$. canadensis plants: $\mathrm{CK}(0.000 \mathrm{~g} / \mathrm{ml})$, Low

4 concentration $(0.0125 \mathrm{~g} / \mathrm{ml})$ and High concentration $(0.2 \mathrm{~g} / \mathrm{ml})$

5

6

7

8

\begin{tabular}{cccc}
\hline Variation source & $d f$ & $F$ & $P^{Z}$ \\
\hline & \multicolumn{2}{c}{ Light-saturated photosynthesis rate } & \\
Treatment & 2 & 0.095 & $0.91^{\mathrm{ns}}$ \\
Day & 3 & 3.859 & $0.022^{*}$ \\
Treatment $\times$ day & 6 & 0.055 & $0.999^{\mathrm{ns}}$ \\
& & Apparent quantum efficiency & \\
Treatment & 2 & 0.05 & $0.951^{\mathrm{ns}}$ \\
Day & 3 & 2.653 & $0.072^{\mathrm{ns}}$ \\
Treatment $\times$ day & 6 & 0.043 & $0.96^{\mathrm{ns}}$ \\
& & Leaf dark respiration rate & \\
Treatment & & 5.856 & $0.004^{* *}$ \\
Day & 3 & 2.261 & $0.126^{\mathrm{ns}}$ \\
Treatment $\times$ day & 6 & 0.968 & $0.467^{\mathrm{ns}}$ \\
\hline
\end{tabular}

